\title{
Study on the Method of Orchestra Rehearsal in Colleges and Universities
}

\author{
Yihua Yuan \\ College of Music, China West Normal University, Nanchong, 637000, China
}

\author{
Keywords: Institutions of higher learning, Orchestra, Rehearsal methods
}

\begin{abstract}
Due to the rapid development of society, more and more attention to the education cause, which largely increased the level of the institutions of higher learning, in the process of development of colleges and universities, it is necessary to develop students' humanistic quality, the most effective way is an art, the orchestra can results in a certain extent, improve the quality education in colleges and universities, the campus cultural atmosphere, and has gradually for the development of institutions of higher learning of the second classroom, in rich and colorful activities for students can feel the charm of orchestral music, enables the all-round development of students' comprehensive quality, students can according to their own interest, rational selection and training of different instruments, develops the student personalization and own quality.
\end{abstract}

\section{Introduction}

At present, most colleges and universities are attaches great importance to the professional quality of education, would be appropriate to ignore the importance of music aesthetic education in the western countries, both vocational colleges and ordinary university, has attached great importance to music aesthetic education, many schools have music aesthetic education early, and have certain specific courses. Began in 1464, for example, the university of Cambridge, UK music appreciation course, the United States in 1870 Harvard University not only established a music class, also as a required subject in the university. Related regulations, points out that if the university have a certain conditions, need to choose at least one of art, and every year in many professional and efficient arrangement at least 18 hours of music aesthetic education classes, this paper mainly analyzes the college orchestra rehearsal method.

\section{The meaning of building a brass band}

\section{Cultivate the students' music quality}

From music skills teaching ways, the basic requirements of quality education and standards not only need to fully comply with to achieve the goal of training play a musical instrument, also from the composition of the basic elements of music to reveal the law of the music and the correct understanding of music, make sure can improve the students' artistic accomplishment, music quality. The Book of LeZhi in Jin, put forward: "to smell its GongSheng, considerate, and wide;... the smell of the plume, ready and frugal and gifts, make the person" this sentence shows that music tune can grasp the people behavior and personality, to some extent the ancients to be able to understand and recognize the music for the role of thought, so modern we must have more fully recognize and grasp the importance of music to shape the talents, cultivating talents.

\section{Improve the students' aesthetic temperament and interest}

Orchestra to sensory edify students touched the evolution for the understanding of art and yearning, can to a certain extent to ensure students to know good and evil, bright dispute, in appreciation of art beauty, to be able to understand nature, to understand the humanities, and social history, in order to be able to get more extensive knowledge, stimulate students' innovation ability and innovation consciousness, while learning to orchestral music, can fully reflect the charm of orchestral music, meet the demand of the actual cognitive, emotional needs and aesthetic needs, and create demand. Sukhomlinskii once said: the implementation of aesthetic education of institutions of higher learning is the basic way and contents of art education, is to improve the basis of social spiritual civilization, to a certain extent, affects students' sentiment, the main way to promote the development of physical and 
mental health, the important part of school education is the art education, cannot replace the significance, whether the social aesthetic needs, or form of aesthetic object, possess corresponding infectious and vivid. Using the specific image of beauty for an art education, through the beautiful and have feelings of melody and colorful images to achieve the purpose of the infected people, which can influence the psychological activities appropriately, make people emotionally resonant.

\section{Promote the development of students' thinking}

It can put people into image thinking and logical thinking, rational thinking on the main characteristics of art education is the ability to develop and improve the training of aesthetic thinking in images, need to have the creativity and imagination, aesthetic time is the most basic quality is actually creation and imagination, image thinking to break must have appropriate constraints, people thought liberation, fully coordinated hands, mouth, ears, eyes, brain and other organs, stimulates the student to develop the diversity of thinking, to have more sensitive organs, the comprehensive development of the student id card memory, understanding, observation, practical ability and imagination. Educators Sukhomlinskii once said: if you don't have poetic aesthetic and emotional spring, will not be able to all-round development of students' intelligence, let the students have to create a poetic aesthetic vision, to have more the beauty of keen perception, wake up and the development of creative thinking.

\section{Institutions of higher learning of the orchestra}

\section{Selection of institutions of higher learning condition of the orchestra}

Colleges and universities students in school has a limited time, a lot of college students is not some music major, selection of colleges and universities student orchestra members to form a band is of great significance, affect the overall development of the orchestra. It needs that teachers of colleges and universities students and the leadership to give certain recommendation and support, and voluntary application ways for choice, use of imitation rhythm, melody, visual, sight singing, such as testing, as the basis of preparation of the orchestra, and combining the students' interest in music, and the corresponding reasonable members of the physical conditions for the rational and scientific selection, this approach can be in a certain extent, promote the healthy and stable development of the orchestra $^{[1] \text {. }}$

\section{The composition of the orchestra in colleges and universities}

The distribution of the instrument

In general, woodwind instruments can be divided into the brass, woodwind, percussion three parts, can also be appropriate to join the bass, keyboard, etc. The brass parts including tenor trombones, horn, time size, large, trumpet, etc.; Woodwind section mainly includes clarinet, flute, saxophone, piccolo; Percussion section includes cymbals, drum, tambourine, castanet, snare drum, Angle iron, etc. Based on the characteristics of the actual development of colleges and universities, the selection and distribution of instruments are for the development of a significant effect on the orchestra. In general, horn price is quite high, volume small, the operation technology is difficult, etc., can use in the preparation of band alto horn to replace, can get better performance. As much as possible the saxophone, because the instrument easy entry, the volume is larger, can quickly get progress and development, at the time of preparation of band, can be equipped with a tenor and soprano, tenor to reasonable debugging saxophone, sax can effective fusion of brass, woodwind, and Bridges ${ }^{[2]}$.

The compiling principle of the band

Based on actual conditions can form different orchestra, but can small, there is no clear strict specification. According to the situation of comprehensive colleges and universities, to establish the corresponding band form, in general, when set up in colleges and universities the orchestra principle can analyze the following aspects:

First, the balance of parts: low, medium and high on the instrument volume can balance and avoid the heavy parts light phenomenon, thus affecting the whole effect.

Second, clear theme, regardless of size, all need to be equipped with the appropriate number of melody instruments, to ensure that is a clear tune, copper tube is mainly tenor and trumpet, wind is mainly the clarinet. 
Third, indoor and outdoor venues, in does not affect the balance on the basis of the establishment band, to give full consideration to the band of the actual use, and flexible and adjust in time, for example, if the band in the outdoor show, often need to appropriately increase the brass, if often play indoors, need reasonable increase woodwind instrument.

Table 1. Orchestra establishment of 36 people

\begin{tabular}{|c|c|c|c|c|c|}
\hline $\begin{array}{c}\text { Woodwind } \\
\text { Parts }\end{array}$ & Piece & The Brass Parts & Piece & $\begin{array}{c}\text { Percussion } \\
\text { Voices }\end{array}$ & Piece \\
\hline flute & 3 & trombone & 5 & bass drum & 1 \\
\hline piccolo & 1 & cornet & 2 & side drum & 1 \\
\hline clarinet & 8 & trumpet & 4 & cymbals & 1 \\
\hline oboe & 2 & horn & 4 & bell & 1 \\
\hline bassoon & 2 & alto horn & 5 & $\begin{array}{c}\text { Triangle angle } \\
\text { iron }\end{array}$ & 1 \\
\hline Saxophone B & 2 & baritone & 1 & & \\
\hline Saxophone E & 2 & tenor horn & 4 & & \\
\hline & & Bass Tuba & 2 & & \\
\hline
\end{tabular}

Table 2. Orchestra establishment of 60people

\begin{tabular}{|c|c|c|c|c|c|}
\hline $\begin{array}{c}\text { Woodwind } \\
\text { Parts }\end{array}$ & Piece & $\begin{array}{c}\text { The Brass } \\
\text { Parts }\end{array}$ & Piece & $\begin{array}{c}\text { Percussion } \\
\text { Voices }\end{array}$ & Piece \\
\hline flute & 3 & trombone & 5 & bass drum & 1 \\
\hline piccolo & 1 & cornet & 2 & side drum & 1 \\
\hline clarinet & 8 & trumpet & 6 & cymbals & 1 \\
\hline oboe & 2 & horn & 6 & bell & 1 \\
\hline bassoon & 4 & alto horn & 5 & $\begin{array}{c}\text { Triangle angle } \\
\text { iron }\end{array}$ & 1 \\
\hline Saxophone B & 2 & baritone & 1 & & \\
\hline Saxophone E & 2 & tenor horn & 4 & & \\
\hline & & Bass Tuba & 2 & & \\
\hline
\end{tabular}

\section{The orchestra's training in colleges and universities}

\section{Basic music theory knowledge learning}

Before the formal training college orchestra, need to organize the band members learn music theory knowledge. Under normal circumstances, the students in colleges and universities have more bad music foundation, therefore, need from chords to start, let the students to understand Arabic Numbers 1, 2, 3, 4, 5, 6, 7 in the music represents the different vibrations of seven syllables. Every day music lesson should be to let the students listen, sing, sing; in music teaching, can put the concept of digital concept into a pitch and roll call. After analyzing the concept of pitch and roll call, should teach students further, seven notes on the score of the reasonable application. If there is a lower or higher, need to in the above seven notes below or above and a dot. For example, compared with 1, I have high octave. Music knowledge and so on need or understand the concept of mechanical memory, if only through the primary and secondary teaching, can't let the students fully understand and master, need to use has risen in a spiral, repeatedly, to ensure that students can remember and master notes, after long time learning and practicing, can let the students know more simple syllables and position on the staff, staff and syllable also need to know the high system and appropriate treble clef. Contrast on staff and chords, in order to improve the students to understand the do, re, mi, such as the extent of the decision, based on this, for students to join d, CRT and length of notes, staff ensure that students can understand ${ }^{[3]}$.

\section{The basic training of orchestra}

Basic training includes two parts of the orchestra, collective play and individual play. The orchestra consists of many members, only by constantly improve each member's own quality, to 
ensure that the overall improve the quality of the band, so each team members need to attach great importance to the training.

Basic training for orchestra

In general, players basic training including: long tongue sound practice, practice, scales and endurance training etc.

First is that endurance exercise. If the players can't accurately grasp the intonation without endurance and strength, there is no corresponding expressive force, often practice playing long tone is a more effective way to improve endurance.

Second, long sound practice. In general, start from the lowest note, order for ascending scale type, until you can play out all soprano, in turn next time meet minimum sound, in the process of practice, the need to guarantee a uniform exhaling breath, every sound smooth, clear note head tail, balanced sound volume, cannot appear weak and strong.

Third, play scales. It needs to be able to master fingering, ensure smoothly in different tonality music playing. In the process of practice, should be from less rise (drop) mark tunes, and to strengthen gradually, until can master and use often use play fingering of the scale.

Fourth, practice tonguing. Use tongue inside the mouth movement, and thus can be cooperate with tongue way, and air flow in the play, the tongue is basically only two actions, including recycling approach and stretching forward. To recycle all, need to keep elastic, decisive, strong; Need to relax, natural stretch forward. Tongue can be divided into three kinds of methods, including tk, single spit, three times Tu. All instruments need to be practicing method of the single spit; small compare attaches great importance to the training three times Tu and tk. The single spit is playing, they first placed the tip of the tongue on the gums, inhale, exhale, under the tip of the tongue to play action is similar to "tu" sound, the process of continuous single spit, need to repeat the action. Tk is after finish single spit, join the indented tongue action, prompting the tip of the tongue in the gums, uplift the back of the tongue, "ke" sound similar to the hair, before and after the two consecutive actions, similar to "tk" syllable. Three times Tu method is combined with tk and single method is similar to a "TKT" or "TTK" sound ${ }^{[4]}$.

Training the orchestra ensemble

Training at the beginning, the orchestra need based ensemble attaches great importance to the training, can from the following several aspects:

First is that the individual practice. At the time of exercise, need attention points spectrum play the difficulty, and slowly practice, gradually overcome the play of suffering, to ensure that have the skilled level. Personal practice is mainly familiar with spectrum, and can perform smooth and accurate.

Second is the division of the practice. A practice division can use a variety of forms, based on the pitch or practice division instrument types. Division of the practice is the fundamental rules, have a certain rhythm and intonation, accurate tone; the volume of the balance, such ability can guarantee the orchestra to achieve the purpose of pleasing to the ear, coordination as a whole. So, for the rest of the band, the division of the practice is very important.

Third is the whole ensemble training. Before playing, need to get ready, for example, the intonation of calibration. Inspection instruments, ensemble, generally is the use of continuous full try to play slow. If discover fault, intonation problem, need to correct, timely complete the try to play, timely solve[5] .

\section{Conclusion}

In a nutshell, builds the orchestra in institutions of higher learning, is the project need to insist for a long time, the teacher needs to the corresponding materials according to different levels of students, on the basis of unit 1, step by step, from difficult to easy ways to form the orchestra, build a good artistic temperament not only, also have good orchestra performing skills, the development of colleges and universities after a certain foundation and the guarantee. 


\section{References}

[1] Liu Zaisheng. Command that subliming the theory of practice - profile Piao DongSheng the command rehearsal notes - China national orchestra sound integration and tone control. People's music,2013(11):85-87.

[2] Jin Ye. Orchestra as Chinese and western art sound the legal - to Piao DongSheng "command rehearsal notes" of learning and thinking. Journal of symphony - journal of xi 'an college of music, 2014,33(2):153-156.D

[3] Ma Xisai. National orchestra and the comparative analysis of western orchestra sound source, the flute concerto "pale", for example. Journal of music creation,2014(2):126-128.

[4] Li Limin.. National orchestra and the comparative analysis of western orchestra sound source, the flute concerto "pale", for example. Journal of music creation,2015(2):55-57.

[5] Sun A' nan. The spirit of Chinese traditional music properly integrated into the national orchestra - read Peng Li famous national orchestral music art research inductive. Journal of music time and space,2014(8):189-189. 